\title{
Factors Influencing Environmental Sanitation among Undergraduates at UiTM, Tapah Campus
}

\author{
Ilya Zulaikha Zulkifli, Nurul Husna Jamian, Faridah Zulkipli
}

\begin{abstract}
Environmental sanitation is an essential process of gathering all types of waste and disposing it in order to protect and promote healthy lifestyle among communities for better quality of life. Sanitation is a key of public health where its roles to reduce the rates of morbidity, spread of disease such diarrhea, and can improve the quality of life of communities particularly among children in developing countries. Lack of sanitation is a challenge among developing countries even in rural or urban area as the increasing of population from 2000 to 2030 is expected to double. There is a significant correlation between knowledge of sanitation and education. Thus, this study sought to study the level of Knowledge, Attitude, Perception, Awareness and Practices based on undergraduates' responses towards Environmental Sanitation. A total of 354 undergraduates from Universiti Teknologi MARA (UiTM), Perak Branch, Tapah Campus cross programs were involved in this study. The responses analyzed using Multiple Linear Regression to achieve the objective stated. The results revealed that three factors contribute towards Environmental sanitation such as Knowledge, Practice and Awareness.
\end{abstract}

Keywords: Attitude, perception, environmental sanitation, knowledge, practice.

\section{INTRODUCTION}

Sanitation and health such in good hygiene and safe water led to social and economic development [1]. Environmental sanitation is an essential process of collecting all types of waste and disposing it with the aim of protecting and promoting the people's healthy lifestyle to achieve quality of life. Generally, it involves the preparation of facilities and provides services for maintenance work of sanitation and to prevent the disease as well [2].

Sanitation routine practices as a key public health where it spurs on to lessen the rates of morbidity, spread of disease such diarrhea, and can enhance the quality of life of communities particularly among children in developing countries [3].

In addition, there is an association between poverty, child infancy and diseases with inadequate sanitation. It means that insufficient sanitation can pose a significant public health risk and has substantial impact on children who are most vulnerable to ill health [4].

Referring to World Health Organization, a particularz

Revised Version Manuscript Received on September 16, 2019.

Ilya Zulaikha Zulkifli, Statistics Department, Faculty of Computer and Mathematical Sciences, Universiti Teknologi MARA, Perak Branch, Tapah Campus, 35400 Tapah Road, Perak, Malaysia.

Nurul Husna Jamian, Statistics Department, Faculty of Computer and Mathematical Sciences, Universiti Teknologi MARA, Perak Branch, Tapah Campus, 35400 Tapah Road, Perak, Malaysia.

Faridah Zulkipli, Statistics Department, Faculty of Computer and Mathematical Sciences, Universiti Teknologi MARA, Perak Branch, Tapah Campus, 35400 Tapah Road, Perak, Malaysia. country can get a return almost 5.5 USD benefits from lower health costs and premature death, plus more productivity for every 1 USD spent in sanitation [5]. Then, a report by [6] stated that almost half of the urban population of Asia, Africa and Latin America have disease spread due to poor sanitation, hygiene and water. Globally, more than 700 million urban residents lack improved sanitation [7]. It is a big challenge actually in developing countries due to lack of sanitation among communities even in rural or urban area that plus the increasing of population from 2000 to 2030 is expected to double.

It observed a significant correlation between education level and comprehension of sanitation where formal education produces educated persons who are knowledgeable and matured to think and make correct decisions. Therefore, the education that related to this issue is good for students because it is expected to create a positives vibe towards environment [8].

Student is a young generation that will contribute to the issue of the environment. The positive or negative contributions depend on what they believe and practice. This is why a good education for the students can make the future of the environmental quality at the best level. It is certain that when people well educate, their awareness level towards environmental care will be high. Hence, the aim of this study is to investigate the level of Knowledge, Attitude, Perception, Awareness and Practices based on undergraduates' responses towards on Environmental Sanitation.

\section{LITERATURE REVIEW}

A previous study by [9] aims to investigate the contributions of gender, knowledge, practice, attitude, and perception of students towards awareness of environmental care. It revealed that gender, knowledge, perception and attitude contributes the awareness on environmental care.

Then other study by [10] aims to plan strategies to improve knowledge, attitude, practices, and self-assessments towards environmental sanitation. Regarding to waste management, majority of people still not isolating the waste before throwing away it where mostly was organic or easy to decay materials whilst for disposal practice was open dumping.

A finding by [10] reported that a majority of the peoples had moderate level of knowledge about environmental 
sanitation and they identified that usually people received the related information from electronic mass media such as television, radio and from community meetings similarly found in [11].

A study by [10] then found that most of the people had poor level of practice towards environmental sanitation. However, majority of them still agree that every person should practice sanitation such as ensure surfaces and floors are washed and communities should set a day for general clean-up and make it as routine. Furthermore, it is good to teach the students about community sanitation in schools.

In addition, a study by [10] also stated that most of the people had moderate level of good attitude towards environmental sanitation. While for Perception, most of respondents were ranked from moderate to good. People were concern about relation between environmental sanitation and health where they aware the impact of inappropriate sanitation practices which might cause a place for criminal hideouts.

\section{METHODOLOGY}

A secondary data had been used to investigate the contribution of some factors towards environmental sanitation. A total of 354 undergraduates from Universiti Teknologi MARA (UiTM), Perak Branch, Tapah Campus was involved in this study. The sample of students was selected conveniently from different programs in Faculty of Computer and Mathematical Sciences (FSKM) [12], [13].

There are six variables involved in this study which are Knowledge, Practice, Attitude, Perception, Awareness and Environmental Sanitation. Multiple Linear Regression analysis is performed using IBM SPSS version 23. Fig. 1 shows the illustration of the theoretical framework considered in this study. In the part of descriptive analysis, assumptions of the regression will be further discussed.

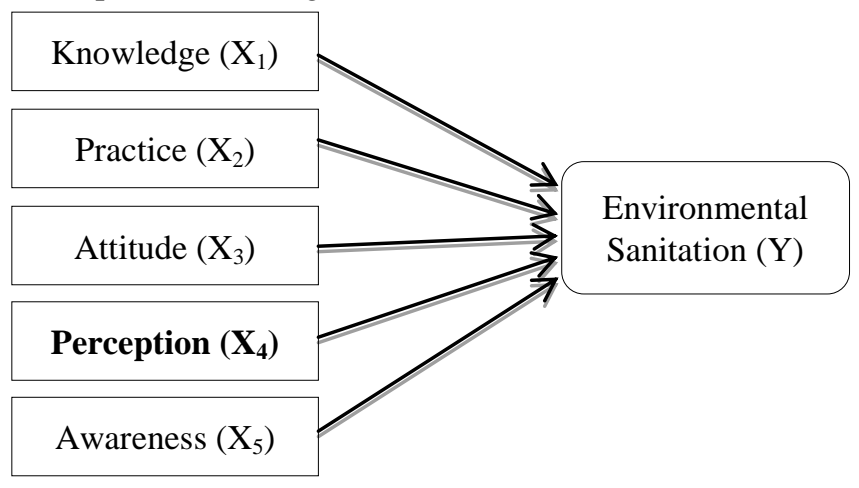

Fig. 1: Theoretical framework of the study

Multiple linear regression analysis is a statistical technique that allows investigating more than one independent variable with the dependent variable [8]. The independent variables measured in this study are Knowledge, Practice, Attitude, Perception and Awareness while the dependent variable is the Environmental Sanitation. For this analysis, the assumptions of multiple linear regression are first explored.

The hypothesis that being setting and tested in this study is as follows:

\section{HO:}

Knowledge, Practice, Attitude, Perception and Awareness of the students are not affecting Environmental Sanitation.

\section{$H_{1}$ :}

Knowledge, Practice, Attitude, Perception and Awareness of the students are affecting Environmental Sanitation.

The $\mathrm{H}_{0}$ will be rejected if $\mathrm{p}$-value $\leq$ significance value $(\alpha)$ $=0.05$ [8]. It indicated the variable(s) is significantly affecting environmental sanitation. The multiple linear regression model is as in (1).

$$
Y=\beta_{0}+\beta_{1} X_{1}+\beta_{2} X_{2} \ldots+\beta_{n} X_{n}+\varepsilon
$$

where $Y$ is the dependent variable, $X_{1}, X_{2}, \ldots, X_{n}$ are the independent variables, $\varepsilon$ is the residual term while the $\beta$ 's are the regression coefficients with $\beta_{0}$ is the constant term. There are four assumptions of the regression analysis must be met in order to make the analysis reliable and valid. The assumptions are as follow:

a) The values of the residuals are normally distributed.

b) The values of the residuals are independent.

c) No multicollinearity exists.

d) There is no outlier exist in dependent variable.

\section{RESULTS AND DISCUSSION}

\section{Assumptions of Multiple Linear Regression}

\section{Results of normality test of the residuals}

The normal P-P plot for the residuals of the model has been constructed to test for the normality as shown in Fig. 2. The closer the dots lie to the diagonal line, the closer to normal the residuals are distributed. In this case, the assumption of the normality for the residuals is not violated since all the dots closer to the diagonal line.

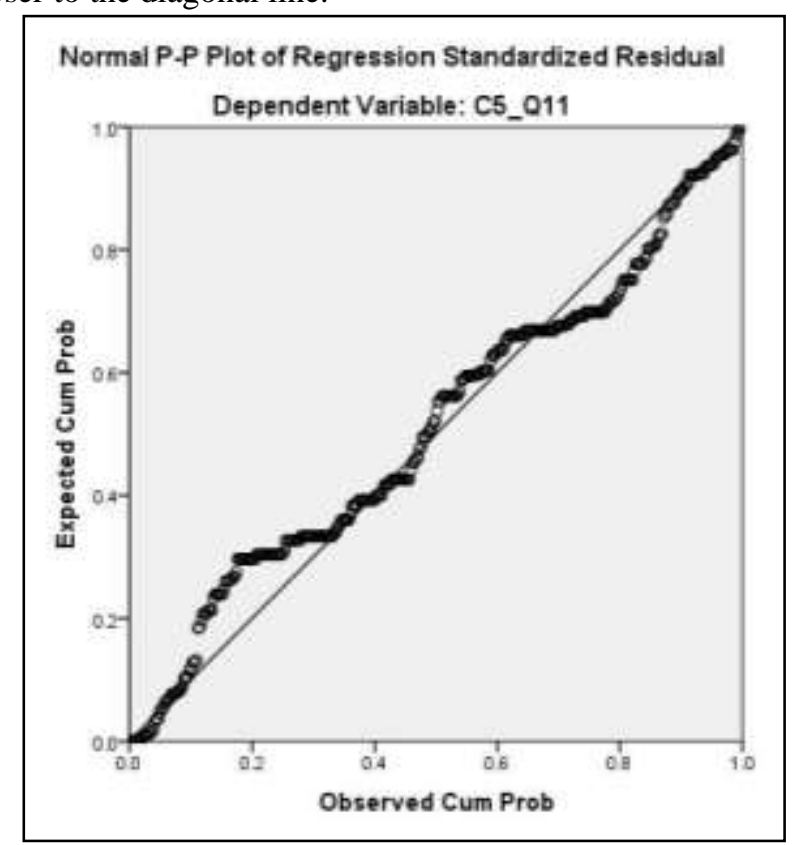

Fig. 2: The normal P-P plot for the residuals of the model 


\section{Results of the independent for the residuals}

Durbin-Watson statistic was used to test for the assumption of residuals to be independent or uncorrelated. This study obtained the Durbin-Watson statistics was 1.019, it indicated the independent for the residuals assumption since the value is between 1 and 3 .

\section{Results of multicollinearity test}

The collinearity statistics showed in Table 1 are used to test the existence of multicollinearity. Analysis of collinearity statistics showed this assumption are met, as VIF scores were below 10 and tolerance scores above 0.2 . Thus, there is no multicollinearity exists in the data.

Table 1: Collinearity statistics

\begin{tabular}{|c|c|c|}
\hline \multirow{2}{*}{ Variables } & \multicolumn{2}{|c|}{ Collinearity Statistics } \\
\cline { 2 - 3 } & Tolerance & VIF \\
\hline Knowledge & 0.944 & 1.059 \\
\hline Practice & 0.901 & 1.110 \\
\hline Attitude & 0.941 & 1.063 \\
\hline Perception & 0.960 & 1.042 \\
\hline Awareness & 0.942 & 1.061 \\
\hline
\end{tabular}

Results of the existence for the outliers

Based on Table 2, Cook's Distance values were all under 1, suggesting individual cases were not improperly influencing the model. This indicates no significance outliers exist which may influence the model.

Table 2: Residuals statistics

\begin{tabular}{|c|c|}
\hline Cook's Distance & Statistics \\
\hline Minimum & 0.000 \\
\hline Maximum & 0.079 \\
\hline Mean & 0.004 \\
\hline Std. Deviation & 0.009 \\
\hline $\mathrm{N}$ & 354 \\
\hline
\end{tabular}

Multiple linear regression analysis

The F-Statistics obtained was 50.549 with p-value less than 0.05 indicating that the estimated regression is valid and is statistically significant at the significance level of 0.05 . Based on Table 3, the regression results showed that Knowledge, Practice and Awareness are significant at the level of 0.05. This implies that Knowledge, Practice and Awareness are significantly affecting the Environmental Sanitation among students. Knowledge, Practice and Sanitation. The estimated coefficients are $0.124,0.144$ and 0.512 respectively. Thus, we reject the null hypothesis and state that Knowledge, Practice and Awareness have an impact on Environmental Sanitation among students. The equation was written as in (2).

$$
\hat{Y}=1.191+0.124 X_{1}+0.144 X_{2}+0.512 X_{5}
$$

The 0.124 associated with environmental sanitation indicates that for each additional in level of knowledge, environmental sanitation level will increase 0.124 , if the other independent variables are held constant. Then for each additional in practice, environmental sanitation level will increase 0.144 , if the other independent variables are held constant. Lastly for awareness, every 1 level increase in awareness, environmental sanitation level will increase 0.512 , if the other independent variables remain constant. Awareness are positively correlated with Environmental

Table 3: Regression analysis results

\begin{tabular}{|c|c|c|c|c|}
\hline Model & B & $\begin{array}{c}\text { Std. } \\
\text { Error }\end{array}$ & $\mathbf{t}$ & p-Value \\
\hline$\beta_{0}$ & $\begin{array}{c}1.19 \\
1\end{array}$ & 0.334 & 3.571 & $\begin{array}{c}0.000^{* *} \\
*\end{array}$ \\
\hline $\mathrm{X}_{1}$ & $\begin{array}{c}0.12 \\
4\end{array}$ & 0.057 & 2.175 & $\begin{array}{c}0.030^{* *} \\
*\end{array}$ \\
\hline $\mathrm{X}_{2}$ & $\begin{array}{c}0.14 \\
4\end{array}$ & 0.048 & 3.016 & $\begin{array}{c}0.003^{* *} \\
*\end{array}$ \\
\hline $\mathrm{X}_{3}$ & $\begin{array}{c}-0.01 \\
0\end{array}$ & 0.040 & -0.260 & 0.795 \\
\hline $\mathrm{X}_{4}$ & $\begin{array}{c}-0.04 \\
4\end{array}$ & 0.033 & -1.321 & 0.187 \\
\hline $\mathrm{X}_{5}$ & $\begin{array}{c}0.51 \\
2\end{array}$ & 0.037 & 13.981 & $\begin{array}{c}0.000^{* *} \\
*\end{array}$ \\
\hline
\end{tabular}

Note: $* * * \mathbf{p}$-value $\leq \mathbf{0 . 0 5}$

\section{CONCLUSION}

This study primarily focused on the factors affecting awareness level among students towards environmental care. Multiple linear regression analysis that had been carried out concluded that knowledge, practice and attitude of the students significantly affecting the environmental sanitation. The three factors were mainly come from education system. Self-concern is needed in the behavioral change towards environmental sanitation where all individuals should take part in this issue to ensure clean and green environment success. It is a message for academicians to educate and intensify the students' attitude and perception towards environmental sanitation.

\section{ACKNOWLEDGMENT}

The authors would like to thank Faculty of Computer and Mathematical Sciences (FSKM) and Universiti Teknologi MARA (UiTM), Perak Branch, Tapah Campus for giving them the opportunity, funding and providing the facilities that helped to perform the study successfully. Heartfelt thanks also go out to lecturers, staff and students for their contribution and support during the survey process.

\section{REFERENCES}

1. M. Singh, Opening address to the third South Asian Conference on Sanitation, New Delhi, 2008

2. World Health Organization (WHO), Sanitation. Available: http://www.who.int/topics/sanitation/en/.

3. Esrey, A. Steven, J. B. Potash, L. Roberts, and C. Shiff, "Effects of improved water supply and sanitation on ascariasis, diarrhoea, dracunculiasis, hookworm infection, schistosomiasis, and trachoma," Bulletin of the World Health organization, 69(5), 1991, pp. 609-612.

4. A. Pruss-Ustun, B. Robert, G. Fiona, and B. Jamie, Safer water, better health: Costs, benefits and sustainability of interventions to protect and promote health. Geneva: World Health Organization, 2008.

5. World Health Organization (WHO), Sanitation fact sheet. Available: http://www.who.int/mediacentre/factsheets/fs392/en/.

6. D. Satterthwaite, "Creating healthy cities in the $21 \mathrm{st}$ 
century," The Earthscan Reader, 1999, pp. 137-172.

7. World Health Organization, WHO/UNICEF, Joint Water Supply, and Sanitation Monitoring Programme. Progress on sanitation and drinking water: 2015 update and MDG assessment. Geneva: WHO, 2015.

8. Hassan, Arbaat, N. Abd Rahman, and S. I. S. S. Abdullah, The level of environmental knowledge, awareness, attitudes and practices among UKM students. 2011, Available:

http://tree.utm.my/wp-content/uploads/2013/03/THE-LE VEL-OF-ENVIRONMENTAL-KNOWLEDGE-AWAR ENESS-ATTITUDES-and-practices-among-ukm-student s.pdf.

9. F. Zulkipli, N. H. Jamian, I. Z. Zulkifli, and Z. Mohd Nopiah, "Logistic regression analysis for awareness among students towards environmental care in UiTM, Tapah Campus," Multidisciplinary Informatics Journal, 2(1), 2019, pp. 74-81.

10. B. C. Duru, C. I. Anthony, C. D. Kevin, A. U. Kenechi, A. M. Irene, C. M. Ugochukwu, N. O. Ijeoma, U. N. Emmanuel, O. Ikechi, and N. Ernest, "Environmental sanitation practices: A case study of solid waste management in semi-urban communities in Orlu, Imo State Nigeria," Occupational Diseases and Environmental Medicine, 5(4), 2017, pp. 88-105.

11. P. O. U. Adogu, K. A. Uwakwe, N. B. Egenti, A. P. Okwuoha, and I. B. Nkwocha, "Assessment of waste management practices among residents of Owerri Municipal Imo State Nigeria," Journal of Environmental Protection, 6(5), 2015, pp. 446-456.

12. N. H. Jamian, F. Zulkipli, I. Z. Zulkifli, and Z. Mohd Nopiah, "Survey on environmental care among UiTM Campus Tapah student on solid waste management using mean score and t-test analysis," International Journal of Engineering and Technology (UAE), 7(4), 2018, pp. 114-118.

13. F. Zulkipli, N. H. Jamian, I. Z. Zulkifli, and Z. Mohd Nopiah, "Investigation on environmental care towards sustainable solid waste management using exploratory factor analysis at UiTM Tapah Campus," Multidisciplinary Informatics Journal, 1(1), 2018, pp. 1-8. 